\title{
NET TROPHIC TRANSFER EFFICIENCIES OF POLYCHLORINATED BIPHENYL CONGENERS TO LAKE TROUT (SALVELINUS NAMAYCUSH) FROM ITS PREY
}

\author{
Charles P. Madenjian, ${ }^{*} †$ Solomon R. David, $\ddagger$ Richard R. Rediske, $§$ and James P. O’Keefe \\ $\dagger$ U.S. Geological Survey, Great Lakes Science Center, Ann Arbor, Michigan \\ $\ddagger$ School of Natural Resources and Environment, University of Michigan, Ann Arbor, Michigan, USA \\ §rand Valley State University, Annis Water Resources Institute, Muskegon, Michigan, USA
}

(Submitted 31 March 2012; Returned for Revision 14 July 2012; Accepted 2 August 2012)

\begin{abstract}
Lake trout (Salvelinus namaycush) were fed bloater (Coregonus hoyi) in eight laboratory tanks over a 135-d experiment. At the start of the experiment, four to nine fish in each tank were sacrificed, and the concentrations of 75 polychlorinated biphenyl (PCB) congeners within these fish were determined. Polychlorinated biphenyl congener concentrations were also determined in the 10 lake trout remaining in each of the eight tanks at the end of the experiment as well as in the bloater fed to the lake trout. Each lake trout was weighed at the start and the end of the experiment, and the amount of food eaten by the lake trout was recorded. Using these measurements, net trophic transfer efficiency $(\gamma)$ from the bloater to the lake trout in each of the eight tanks was calculated for each of the 75 congeners. Results showed that $\gamma$ did not vary significantly with the degree of chlorination of the PCB congeners, and $\gamma$ averaged 0.66 across all congeners. However, $\gamma$ did show a slight, but significant, decrease as $\log K_{\mathrm{OW}}$ increased from 6.0 to 8.2. Activity level of the lake trout did not have a significant effect on $\gamma$. Environ. Toxicol. Chem. 2012;31:2821-2827. (C) 2012 SETAC
\end{abstract}

Keywords-Trophic transfer efficiency Polychlorinated biphenyl congeners Lake trout

\section{INTRODUCTION}

An important factor regulating contaminant accumulation in a fish is the efficiency with which the fish retains contaminants from its prey [1-3]. Consequently, reliable estimates of the efficiency with which fish retain contaminants from their food are essential for use in risk assessment models to predict future risks to both people and wildlife eating contaminated fish under various scenarios of environmental contamination [4].

Gross trophic transfer efficiency can be defined as the efficiency with which the contaminant in the food ingested by the predator is transported through the gut wall [5]. Once transported through the gut wall, portions of the quantity of the contaminant inside the body of the predator may eventually be lost through depuration or metabolic transformation. Net trophic transfer efficiency is the efficiency with which the contaminant in the food ingested by the predator is retained by the predator, including any losses attributable to elimination and metabolic transformation [6].

Gobas et al. [7] and Thomann [3] proposed that gross trophic transfer efficiency of organic contaminants to fish from their prey is a function of the contaminant's lipid affiliation, as measured by the octanol-water partition coefficient, $K_{\mathrm{OW}}$. Thomann [3] fitted an empirical relationship to estimates of gross trophic transfer efficiencies to fish from their prey for various organic contaminants as a function of $\log K_{\mathrm{OW}}$. According to the fitted relationship, gross trophic transfer efficiency remained at a high level when $\log K_{\text {Ow }}$ ranged from 5 to 6 but then decreased exponentially as $\log K_{\text {OW }}$ increased from 6 to 10 , and this exponential rate of decrease was estimated at $50 \%$ per unit of $\log K_{\mathrm{OW}}$.

All Supplemental Data may be found in the online version of this article.

* To whom correspondence may be addressed (cmadenjian@usgs.gov).

Published online 24 August 2012 in Wiley Online Library (wileyonlinelibrary.com).
However, the available estimates for both gross and net trophic transfer efficiencies of polychlorinated biphenyl (PCB) congeners to fish from their prey indicated that trophic transfer efficiency was strongly influenced by $\log K_{\mathrm{OW}}$ in one case but not in four other cases. For the case of lake whitefish (Coregonus clupeaformis) feeding on rainbow smelt (Osmerus mordax) during a laboratory experiment, estimates of net trophic transfer efficiency of the various PCB congeners plotted against $\log K_{\mathrm{OW}}$ exhibited a pattern similar to the one proposed by Thomann [8]. In contrast, estimates of net trophic transfer efficiency of PCB congeners to Atlantic salmon (Salmo salar) from their pelleted food exhibited no significant relationship with $\log K_{\mathrm{OW}}$ as it ranged from 5.2 to 7.8 [9]. Similarly, estimates of gross trophic transfer efficiency of PCB congeners to rainbow trout from their pelleted food showed a slight increase as $\log K_{\mathrm{OW}}$ increased from 5.0 to 6.5 and then a slight decrease as $\log K_{\mathrm{OW}}$ further increased from 6.5 to 8.0 [10]. Using field data, Madenjian et al. [5] calculated that net trophic transfer efficiency of PCB congeners to Lake Michigan coho salmon (Oncorhynchus kisutch) from their prey increased slightly as $\log K_{\mathrm{OW}}$ increased from 6.2 to 6.6 , but then showed a slight decrease as $\log K_{\mathrm{OW}}$ further increased from 6.6 to 7.9. Based on tests in which rainbow trout contaminated with several different organochlorines were fed to northern pike (Esox lucius) in the laboratory, Burreau et al. [11] estimated that gross trophic transfer efficiency for the PCB congeners slightly increased as $\log K_{\mathrm{OW}}$ increased from 5.7 to 7.0.

Historically, lake trout (Salvelinus namaycush) was the top native predator in the Laurentian Great Lakes, and lake trout populations have supported valuable commercial and recreational fisheries in North America [12-14]. Despite the ecological and economic importance of lake trout populations, to the best of our knowledge, net trophic transfer efficiency of PCB congeners to lake trout from its prey has not been measured in the laboratory. Such measurements are needed to support risk assessments for humans consuming lake trout. 
The goal of the present study was to estimate, in the laboratory, the net trophic transfer efficiencies of PCB congeners to lake trout from its prey. In addition, the applicability of the previously mentioned relationship developed by Thomann [3] to our estimated net trophic transfer efficiencies for lake trout was determined. Furthermore, the effect of lake trout activity on $\gamma$ for the various PCB congeners was investigated. Paterson et al. [15] have suggested that lake trout activity in the Laurentian Great Lakes has recently increased in response to the changing food web. Lake trout in one set of tanks were exercised by subjecting the fish to a relatively high flow rate, while the other lake trout were allowed to remain relatively inactive. To determine the effect of activity on net trophic transfer efficiency, mean $\gamma$ for the active lake trout was compared with mean $\gamma$ for the inactive lake trout for each of the PCB congeners.

\section{MATERIALS AND METHODS}

\section{Laboratory experiment}

The laboratory experiment was conducted from February 16 through July 1, 2010. Lake trout were kept in iron-filtered well water at the Great Lakes Science Center (Ann Arbor, MI, USA) in four 2,380-L and four $870-\mathrm{L}$ circular tanks that had water exchange rates of 15 and $5 \mathrm{~L} / \mathrm{min}$, respectively. Average water velocities in the large tanks, namely tanks $1,2,3$, and 4 , were maintained at $16.1,17.1,14.4$, and $15.6 \mathrm{~cm} / \mathrm{s}$, respectively, using centrifugal pumps. Average water velocities in the small tanks, namely tanks $5,6,7$, and 8 , were $2.9,1.2,2.1$, and $1.5 \mathrm{~cm} /$ $\mathrm{s}$, respectively. Water temperature ranged from 8.3 to $10.0^{\circ} \mathrm{C}$ during the course of the experiment. Tanks 1, 2, 3, 4, 5, 6, 7, and 8 received lots of $19,19,18,18,14,14,16$, and 15 lake trout, respectively. Each lake trout was weighed at the start of the experiment. In addition, 9, 9, 8, 8, 4, 4, 6, and 5 lake trout were sacrificed from tanks $1,2,3,4,5,6,7$, and 8 , respectively. The sacrificed lake trout were frozen, placed in plastic bags, and stored at $-30^{\circ} \mathrm{C}$.

Lake trout in each of the eight tanks were fed thawed bloater (Coregonus hoyi) daily, which had been caught in Lake Michigan during September 2009 and May 2010, frozen, and stored at $-30^{\circ} \mathrm{C}$. The amount of food placed in each tank was weighed to the nearest $0.1 \mathrm{~g}$. All uneaten food was removed from the tanks each day, air dried for $20 \mathrm{~min}$, and weighed to the nearest $0.1 \mathrm{~g}$. Lake trout were fed as much as they would consume during one feeding each day. Lake trout were fed Septembercaught bloater during the first $96 \mathrm{~d}$ of the experiment and during days 105 to 121 , whereas the lake trout were fed May-caught bloater during all other days of the experiment. By weight, $85 \%$ of the food consumed by the lake trout during the entire experiment was September-caught bloater, and the remaining $15 \%$ was May-caught bloater. At the conclusion of the experiment, each of the remaining 10 lake trout in each of the eight tanks was weighed, placed in a plastic bag, and then frozen at $-30^{\circ} \mathrm{C}$ until time of analysis. In addition, 10 three-fish subsamples and 10 six-fish subsamples of the September-caught and May-caught bloater, respectively, were placed in plastic bags and stored at $-30^{\circ} \mathrm{C}$ for later analysis. Refer to Madenjian et al. [16] for more details on the laboratory experiment.

\section{Polychlorinated biphenyl determinations}

Lake trout from the laboratory experiment were grouped by tank and stage of the experiment (start or end). Each of the eight lake trout composites for the start of experiment consisted of four to nine fish (depending on the number of fish sacrificed from the tank at the start of the experiment), whereas each of the eight lake trout composites for the end of the experiment consisted of 10 fish. Each of the 10 composites for the September-caught bloater consisted of three fish, whereas each of the 10 composites for the May-caught bloater consisted of six fish. Each of the 16 lake trout composites and each of the 20 bloater composites were homogenized in a blender. Polychlorinated biphenyl congener concentrations were determined in each of the composite samples using the negative chemical ionization mass spectrometry procedure outlined by Schmidt [17]. The sample preparation procedure involved soxhlet extraction with a 50:50 dichloromethane-hexane mixture followed by use of a multilayered anthropogenic column to remove oils and some interfering coextractables [18]. We calibrated the instrument using individual congener standards, from AccuStandard, at five concentration levels. Concentrations for each of the 89 PCB congeners were determined. All samples were spiked with two non-Arochlor congeners (numbers 65 and 166; International Union of Pure and Applied Chemistry). Calibration accuracy was based on the ability to analyze Arochlor standards and obtain the predicted amounts and ratios obtained by Frame et al. [19]. Additional calibration validation was done using the West Coast Fish Studies standard supplied by AccuStandard. Appropriate quality control samples (blanks, matrix spikes, and duplicates) were analyzed to ensure precision and accuracy. Spike recoveries ranged from 93 to $101 \%$.

\section{Statistical analyses}

We estimated net trophic transfer efficiency, $\gamma$, of each of 75 PCB congeners from bloater to lake trout based on our laboratory experiment results (Table 1). Of the 89 PCB congeners examined, 14 of these congeners co-eluted with other PCB congeners. The co-elutors were not included in our statistical analyses because we wanted to restrict our investigation of relationships between $\gamma$ and the degree of chlorination and between $\gamma$ and $\log K_{\mathrm{OW}}$ to pure chemical compounds. The 75 congeners included in our analyses consisted of four trichloro congeners $(19,22,28$, and 31$)$, nine tetrachloro congeners (44, $45,46,47,52,60,63,70$, and 74), 15 pentachloro congeners $(82,83,85,87,92,95,97,99,101,105,110,115,117,118$, and 124), 17 hexachloro congeners $(128,130,131,134,135,137$, $138,141,144,146,149,151,156,158,163,164$, and 167), 16 heptachloro congeners $(170,171,172,174,175,176,177,178$, $179,180,183,185,187,190,191$, and 193), 10 octochloro congeners $(194,195,196,197,199,200,201,202,203$, and $205)$, three nonachloro congeners (206, 207, and 208), and one decachloro congener (209). The value of $\log K_{\mathrm{OW}}$ ranged from 5.02 to 8.18 for the set of 75 PCB congeners (Table 1).

We calculated $\gamma$ of each of the 75 PCB congeners for each of the eight tanks using the equation

$$
\gamma=\frac{\left(\left[\mathrm{PCB}_{\mathrm{f}}\right] W_{\mathrm{f}}\right)-\left(\left[\mathrm{PCB}_{\mathrm{i}}\right] W_{\mathrm{i}}\right)}{\text { amount of the } \mathrm{PCB} \text { congener ingested }}
$$

where $\left[\mathrm{PCB}_{\mathrm{f}}\right]$ is the average $\mathrm{PCB}$ congener concentration of the lake trout in the tank at the end of the experiment, $W_{\mathrm{f}}$ is the average weight of the lake trout in the tank at the end of the experiment, $\left[\mathrm{PCB}_{\mathrm{i}}\right]$ is the average $\mathrm{PCB}$ congener concentration of the lake trout in the tank at the start of the experiment, $W_{\mathrm{i}}$ is the average weight of the lake trout in the tank at the start of the experiment, and the amount of the PCB congener ingested refers 
Table 1. Logarithm of the octanol-water partition coefficient $\left(\log K_{\mathrm{OW}}\right)$ and number of chlorine atoms per molecule for the 75 polychlorinated biphenyl (PCB) congeners included in the study ${ }^{\mathrm{a}}$

\begin{tabular}{|c|c|c|c|c|c|}
\hline PCB congener & No. of chlorine atoms per molecule & $\log K_{\text {OW }}$ & PCB congener & No. of chlorine atoms per molecule & $\log K_{\text {OW }}$ \\
\hline 19 & 3 & 5.02 & 149 & 6 & 6.67 \\
\hline 22 & 3 & 5.58 & 151 & 6 & 6.64 \\
\hline 28 & 3 & 5.67 & 156 & 6 & 7.18 \\
\hline 31 & 3 & 5.67 & 158 & 6 & 7.02 \\
\hline 44 & 4 & 5.75 & 163 & 6 & 6.99 \\
\hline 45 & 4 & 5.53 & 164 & 6 & 7.02 \\
\hline 46 & 4 & 5.53 & 167 & 6 & 7.27 \\
\hline 47 & 4 & 5.85 & 170 & 7 & 7.27 \\
\hline 52 & 4 & 5.84 & 171 & 7 & 7.11 \\
\hline 60 & 4 & 6.11 & 172 & 7 & 7.33 \\
\hline 63 & 4 & 6.17 & 174 & 7 & 7.11 \\
\hline 70 & 4 & 6.20 & 175 & 7 & 7.17 \\
\hline 74 & 4 & 6.20 & 176 & 7 & 6.76 \\
\hline 82 & 5 & 6.20 & 177 & 7 & 7.08 \\
\hline 83 & 5 & 6.26 & 178 & 7 & 7.14 \\
\hline 85 & 5 & 6.30 & 179 & 7 & 6.73 \\
\hline 87 & 5 & 6.29 & 180 & 7 & 7.36 \\
\hline 92 & 5 & 6.35 & 183 & 7 & 7.20 \\
\hline 95 & 5 & 6.13 & 185 & 7 & 7.11 \\
\hline 97 & 5 & 6.29 & 187 & 7 & 7.17 \\
\hline 99 & 5 & 6.39 & 190 & 7 & 7.46 \\
\hline 101 & 5 & 6.38 & 191 & 7 & 7.55 \\
\hline 105 & 5 & 6.65 & 193 & 7 & 7.52 \\
\hline 110 & 5 & 6.48 & 194 & 8 & 7.80 \\
\hline 115 & 5 & 6.49 & 195 & 8 & 7.56 \\
\hline 117 & 5 & 6.46 & 196 & 8 & 7.65 \\
\hline 118 & 5 & 6.74 & 197 & 8 & 7.30 \\
\hline 124 & 5 & 6.73 & 199 & 8 & 7.62 \\
\hline 128 & 6 & 6.74 & 200 & 8 & 7.20 \\
\hline 130 & 6 & 6.80 & 201 & 8 & 7.27 \\
\hline 131 & 6 & 6.58 & 202 & 8 & 7.24 \\
\hline 134 & 6 & 6.55 & 203 & 8 & 7.65 \\
\hline 135 & 6 & 6.64 & 205 & 8 & 8.00 \\
\hline 137 & 6 & 6.83 & 206 & 9 & 8.09 \\
\hline 138 & 6 & 6.83 & 207 & 9 & 7.74 \\
\hline 141 & 6 & 6.82 & 208 & 9 & 7.71 \\
\hline 144 & 6 & 6.67 & 209 & 10 & 8.18 \\
\hline 146 & 6 & 6.89 & & & \\
\hline
\end{tabular}

${ }^{\text {a }}$ Values of $\log K_{\mathrm{OW}}$ were taken from Hawker and Connell [22]. Numbering of congeners was according to the International Union of Pure and Applied Chemistry (IUPAC) numbering system of PCBs.

to the weight of the PCB congener ingested, on average, by each lake trout in the tank during the course of the experiment. For each PCB congener, we computed the congener's average concentration in both the September-caught and the May-caught bloater. We then used these average congener concentrations for the two batches of bloater, along with the amounts of bloater from both batches eaten by the lake trout in the tank, to calculate the total amount of the PCB congener ingested by the lake trout in the tank. The estimate of $\gamma$ was averaged across all eight tanks for each of the 75 congeners, and a standard error of the mean value was also calculated for each of the 75 congeners.

To determine whether the activity level of the lake trout had a significant effect on net trophic transfer efficiency, we applied a two-sample $t$ test to the eight estimates of $\gamma$ for each of the 75 PCB congeners. More specifically, mean $\gamma$ of the active lake trout (lake trout from tanks 1-4) was compared with mean $\gamma$ of the inactive lake trout (lake trout from tanks 5-8) for each of the 75 PCB congeners. We set $\alpha=0.05$ for all of our statistical testing.

To determine whether degree of chlorination affected $\gamma$, oneway analysis of variance (ANOVA) was used to ascertain whether mean $\gamma$ varied significantly with degree of chlorination $[5,8]$. We included congeners with $3,4,5,6,7,8$, and 9 chlorine atoms per molecule in the ANOVA; the decachloro congener (congener 209) was not included in the ANOVA because only one replicate was available for this category. Each observation in the ANOVA was the value of $\gamma$ averaged across all eight tanks for a particular congener. If the ANOVA results indicated a significant effect of degree of chlorination on $\gamma$, the ANOVA was followed up by a Tukey multiple comparison procedure to determine significant pairwise differences between mean values of $\gamma$.

To determine whether $\log K_{\text {Ow }}$ had a significant influence on $\gamma$, a simple linear regression of $\log \gamma$ as a function of $\log K_{\text {OW }}$ was performed. Significance of the slope of the regression line was assessed with a $t$ test. Because the hypothesis of Thomann [3] was that $\gamma$ decreased exponentially when $\log$ $K_{\text {OW }}$ increased from 6 to 10 , only congeners with $\log K_{\text {OW }}$ greater than 6 were included in this regression analysis. To express our fitted regression equation in terms of $\gamma$ as a function of $\log K_{\mathrm{OW}}$, the estimate of the intercept $a$ was backtransformed by calculating $\mathrm{e}^{a}$. We then plotted the backtransformed version of the fitted regression line, along with the estimates of $\gamma$.

To make our information on the co-elutors available to the scientific community, we calculated $\gamma$ for the co-elutors in the same manner that we calculated $\gamma$ for the 75 PCB congeners that did not co-elute. The estimate of $\gamma$ was averaged across all eight tanks for each of the pairs of co-elutors, and a standard error of 
Table 2. Initial and final average weights of lake trout used in the 135-d laboratory experiment ${ }^{\mathrm{a}}$

\begin{tabular}{lccc}
\hline & \multicolumn{2}{c}{ Average weight of lake trout $(\mathrm{g})$} & \\
\cline { 2 - 3 } $\begin{array}{l}\text { Tank } \\
\text { number }\end{array}$ & Initial & Final & $\begin{array}{c}\text { Consumption } \\
(\mathrm{g})\end{array}$ \\
\hline 1 & 907 & 1,345 & 1,734 \\
2 & 860 & 1,339 & 1,999 \\
3 & 890 & 1,518 & 2,344 \\
4 & 817 & 1,566 & 2,649 \\
5 & 694 & 1,242 & 1,870 \\
6 & 729 & 853 & 641 \\
7 & 754 & 1,050 & 1,203 \\
8 & 729 & 1,092 & 1,336 \\
\hline
\end{tabular}

${ }^{\mathrm{a}}$ Lake trout were fed bloater. Also included is the average amount of food eaten by a lake trout during the entire course of the experiment.

the mean value was also calculated for each of the pairs of coelutors. These estimates are presented in Supplemental Data, Table S1.

\section{RESULTS}

Average initial weights of the lake trout in the eight tanks ranged from 694 to $907 \mathrm{~g}$, whereas average final weights of the lake trout ranged from 853 to $1,566 \mathrm{~g}$ (Table 2). Average food consumption by lake trout over the course of the experiment ranged from 641 to $2,649 \mathrm{~g}$. Average PCB congener concentrations in the lake trout at the start of the experiment ranged from 0.01 to $7.14 \mathrm{ng} / \mathrm{g}$ (wet wt basis), whereas average congener concentrations ranged from 0.03 to $28.31 \mathrm{ng} / \mathrm{g}$ at the end of the experiment (Table 3). Average PCB congener concentrations in the September-caught bloater ranged from 0.03 to $26.56 \mathrm{ng} / \mathrm{g}$, and average PCB congener concentrations in the May-caught bloater ranged from 0.03 to $23.52 \mathrm{ng} / \mathrm{g}$ (Table 3).

Averaging across all eight tanks, estimates of $\gamma$ ranged from 0.309 to 0.988 (Table 4). Standard errors for these estimates ranged from 0.029 to 0.227 . Based on the results of the twosample $t$ tests, activity level of the lake trout did not have a significant effect on $\gamma$ for any of the 75 PCB congeners $(p>0.05)$. Averaging across all 75 congeners, mean $\gamma$ for the active lake trout was equal to 0.681 and mean $\gamma$ for the inactive lake trout was equal to 0.646. Thus, on average, $\gamma$ for the active lake trout was very similar to $\gamma$ for the inactive lake trout.

Net trophic transfer efficiency, $\gamma$, did not vary significantly with degree of chlorination of the PCB congeners (oneway ANOVA: $F=2.16$; degrees of freedom $[d f]=6,67$;

Table 3. Initial and final polychlorinated biphenyl (PCB) congener concentrations in lake trout, averaged across the eight tanks used in the 135-d laboratory experiment ${ }^{\mathrm{a}}$

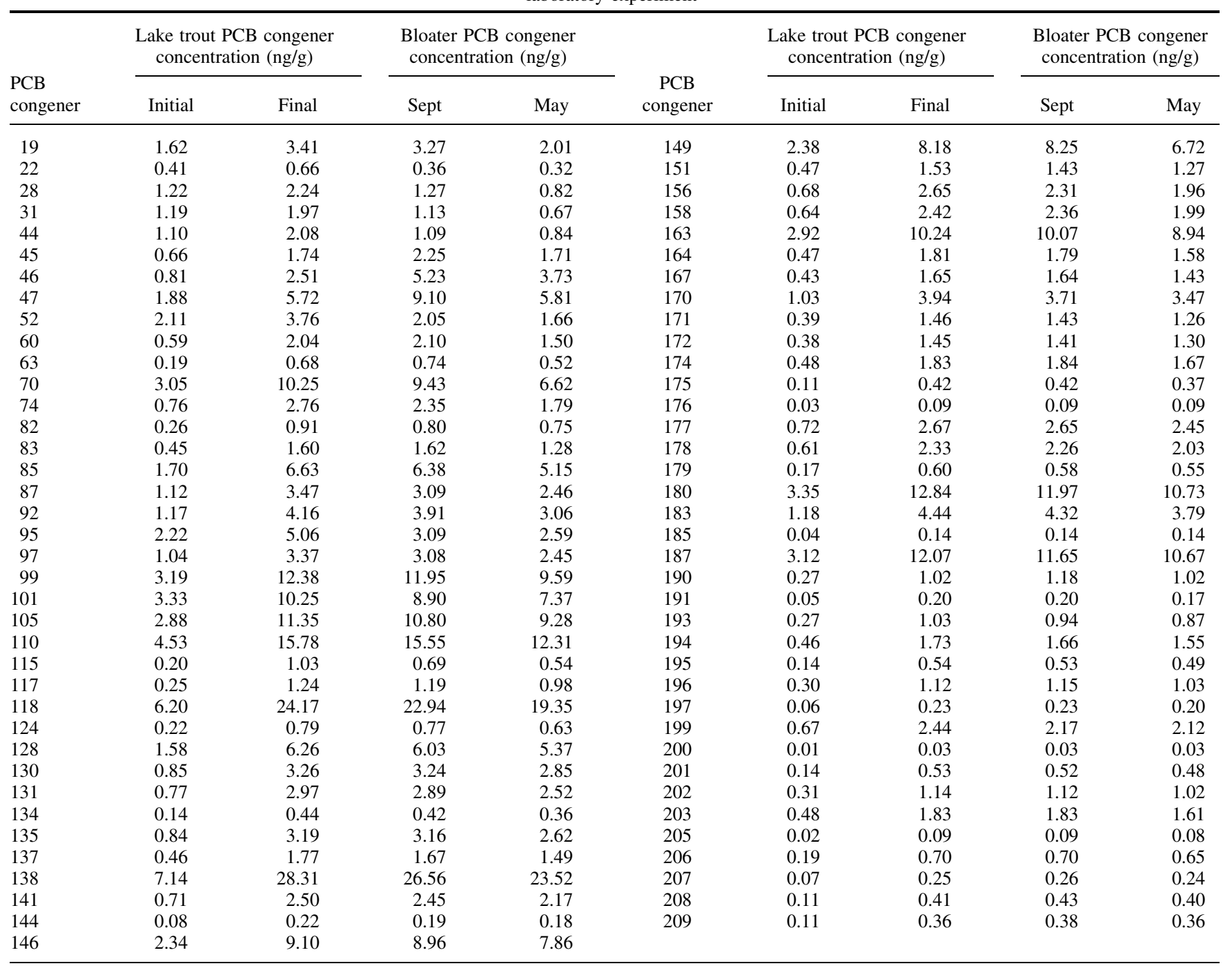

\footnotetext{
${ }^{a}$ Also shown are the average PCB congener concentrations in the September-caught and May-caught bloater fed to the lake trout during the experiment.
} 
Table 4. Mean estimates of net trophic transfer efficiency $(\gamma)$ of polychlorinated biphenyl (PCB) congeners to lake trout from its prey ${ }^{\mathrm{a}}$

\begin{tabular}{|c|c|c|c|c|c|}
\hline \multirow{2}{*}{$\begin{array}{l}\begin{array}{l}\text { PCB } \\
\text { congener }\end{array} \\
19\end{array}$} & \multicolumn{2}{|c|}{ Mean estimate of $\gamma$} & \multirow{2}{*}{$\begin{array}{c}\begin{array}{c}\text { PCB } \\
\text { congener }\end{array} \\
149\end{array}$} & \multicolumn{2}{|c|}{ Mean estimate of $\gamma$} \\
\hline & 0.563 & $(0.046)$ & & 0.628 & $(0.036)$ \\
\hline 22 & 0.813 & $(0.127)$ & 151 & 0.653 & $(0.034)$ \\
\hline 28 & 0.900 & $(0.086)$ & 156 & 0.733 & $(0.051)$ \\
\hline 31 & 0.848 & $(0.065)$ & 158 & 0.657 & $(0.032)$ \\
\hline 44 & 0.988 & $(0.058)$ & 163 & 0.632 & (0.042) \\
\hline 45 & 0.474 & $(0.058)$ & 164 & 0.648 & $(0.035)$ \\
\hline 46 & 0.309 & $(0.035)$ & 167 & 0.642 & $(0.033)$ \\
\hline 47 & 0.401 & $(0.029)$ & 170 & 0.668 & $(0.039)$ \\
\hline 52 & 0.911 & $(0.059)$ & 171 & 0.649 & (0.038) \\
\hline 60 & 0.625 & $(0.034)$ & 172 & 0.649 & $(0.035)$ \\
\hline 63 & 0.596 & $(0.036)$ & 174 & 0.646 & $(0.037)$ \\
\hline 70 & 0.702 & $(0.039)$ & 175 & 0.632 & $(0.038)$ \\
\hline 74 & 0.753 & $(0.050)$ & 176 & 0.636 & $(0.046)$ \\
\hline 82 & 0.700 & $(0.038)$ & 177 & 0.636 & $(0.031)$ \\
\hline 83 & 0.644 & $(0.039)$ & 178 & 0.654 & $(0.040)$ \\
\hline 85 & 0.677 & $(0.037)$ & 179 & 0.647 & $(0.034)$ \\
\hline 87 & 0.699 & $(0.038)$ & 180 & 0.681 & $(0.036)$ \\
\hline 92 & 0.681 & $(0.032)$ & 183 & 0.654 & $(0.038)$ \\
\hline 95 & 0.887 & $(0.102)$ & 185 & 0.611 & $(0.036)$ \\
\hline 97 & 0.683 & $(0.032)$ & 187 & 0.659 & $(0.036)$ \\
\hline 99 & 0.675 & $(0.035)$ & 190 & 0.549 & $(0.031)$ \\
\hline 101 & 0.705 & $(0.035)$ & 191 & 0.629 & $(0.032)$ \\
\hline 105 & 0.678 & $(0.035)$ & 193 & 0.693 & $(0.037)$ \\
\hline 110 & 0.647 & $(0.037)$ & 194 & 0.654 & $(0.035)$ \\
\hline 115 & 0.957 & $(0.227)$ & 195 & 0.643 & $(0.039)$ \\
\hline 117 & 0.704 & $(0.050)$ & 196 & 0.614 & $(0.037)$ \\
\hline 118 & 0.680 & $(0.035)$ & 197 & 0.640 & $(0.040)$ \\
\hline 124 & 0.655 & $(0.037)$ & 199 & 0.696 & $(0.036)$ \\
\hline 128 & 0.666 & $(0.035)$ & 200 & 0.543 & $(0.042)$ \\
\hline 130 & 0.644 & $(0.034)$ & 201 & 0.634 & $(0.040)$ \\
\hline 131 & 0.659 & $(0.037)$ & 202 & 0.639 & $(0.036)$ \\
\hline 134 & 0.646 & $(0.032)$ & 203 & 0.631 & $(0.036)$ \\
\hline 135 & 0.653 & $(0.034)$ & 205 & 0.645 & $(0.038)$ \\
\hline 137 & 0.675 & $(0.035)$ & 206 & 0.617 & $(0.036)$ \\
\hline 138 & 0.686 & $(0.033)$ & 207 & 0.606 & $(0.039)$ \\
\hline 141 & 0.639 & $(0.037)$ & 208 & 0.592 & $(0.038)$ \\
\hline 144 & 0.680 & $(0.050)$ & 209 & 0.570 & $(0.037)$ \\
\hline 146 & 0.650 & $(0.034)$ & & & \\
\hline
\end{tabular}

${ }^{a}$ Estimates were based on a 135-d laboratory experiment, during which bloater were fed to lake trout. For each congener, $\gamma$ estimates from all eight tanks were averaged to yield the mean estimate. Standard error of the mean is enclosed in parentheses.

$p=0.0579)$. Nevertheless, $\gamma$ did show a slight decrease as the degree of chlorination increased from 5 to 10 chlorine atoms per molecule (Fig. 1). The average value of $\gamma$ across all 75 congeners was 0.664 .

Net trophic transfer efficiency, $\gamma$, declined exponentially as $\log K_{\text {OW }}$ increased from 6.0 to 8.2 (Fig. 2). Although the rate of decline was only $7 \%$ per unit of $\log K_{\mathrm{OW}}$, this rate of decline was significantly different from zero ( $t$ test: $t=-4.09$; $d f=64 ; p=0.0001)$. According to the fitted curve, $\gamma$ was equal to 0.70 at $\log K_{\mathrm{OW}}=6$, and $\gamma$ was equal to 0.61 at $\log$ $K_{\mathrm{OW}}=8$ (Fig. 2).

\section{DISCUSSION}

Although our results indicated that $\log K_{\mathrm{OW}}$ had a significant effect on the ability of lake trout to retain PCB congeners from its prey, this effect was relatively weak compared with that for lake whitefish. Madenjian et al. [8] estimated that $\gamma$ decreased at a rate of $33 \%$ per unit of $\log K_{\text {OW }}$ beyond a $\log K_{\text {OW }}$ value of 6 from their laboratory experiment with lake whitefish. Furthermore, this rate of decrease was not significantly different from the hypothetical rate of $50 \%$ per unit of $\log K_{\text {Ow }}$ proposed by

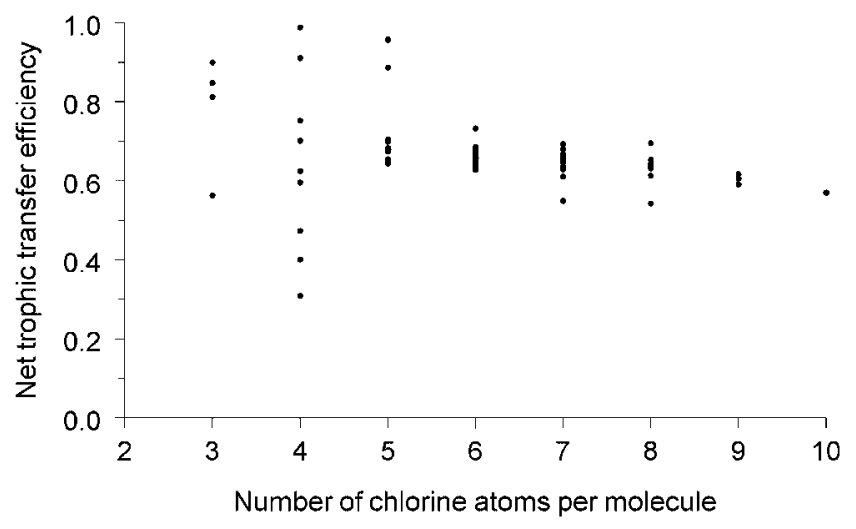

Fig. 1. Estimate of net trophic transfer efficiency $(\gamma)$ of a polychlorinated biphenyl (PCB) congener to lake trout from its prey as a function of the number of chlorine atoms per molecule of the PCB congener. Estimates were based on a laboratory experiment, during which lake trout were fed bloater.

Thomann [3]. In contrast, we estimated that $\gamma$ decreased by only $7 \%$ per unit of $\log K_{\mathrm{OW}}$ in lake trout. Moreover, the $95 \%$ confidence interval about this rate of decrease, $7 \% \pm 4 \%$, indicated that the rate of decrease for lake trout was both far less and significantly less than that estimated for lake whitefish or the hypothetical rate proposed by Thomann [3]. Clearly, the ability of lake trout to retain PCB congeners from its prey was weakly affected by the $\log K_{\mathrm{OW}}$ of the PCB congeners. Thus, lake trout were similar to fishes such as rainbow trout, Atlantic salmon, and coho salmon in their ability to retain PCB congeners from their food, because $\gamma$ was only weakly influenced by the $\log K_{\mathrm{OW}}$ of the PCB congeners. For Atlantic salmon, $\gamma$ for the PCB congeners appeared to be unrelated to $\log K_{\mathrm{OW}}$ of the PCB congeners over the range of 5.2 to 7.8 in $\log K_{\mathrm{OW}}$ values [9]. For both rainbow trout and coho salmon, $\gamma$ showed a slight decrease as $\log K_{\mathrm{OW}}$ increased from 6.5 to 8.0 [5,10]; similarly, $\gamma$ for lake trout slightly decreased over this same range of $\log K_{\mathrm{OW}}$. As suggested by Madenjian et al. [8], perhaps gut uptake of higher chlorinated congeners is enhanced in fishes such as Atlantic salmon, rainbow trout, coho salmon, northern pike, and lake trout, whereas gut uptake of higher chlorinated congeners is not enhanced in fishes such as lake whitefish. In addition, a comparison of gut physiology, biochemistry, and

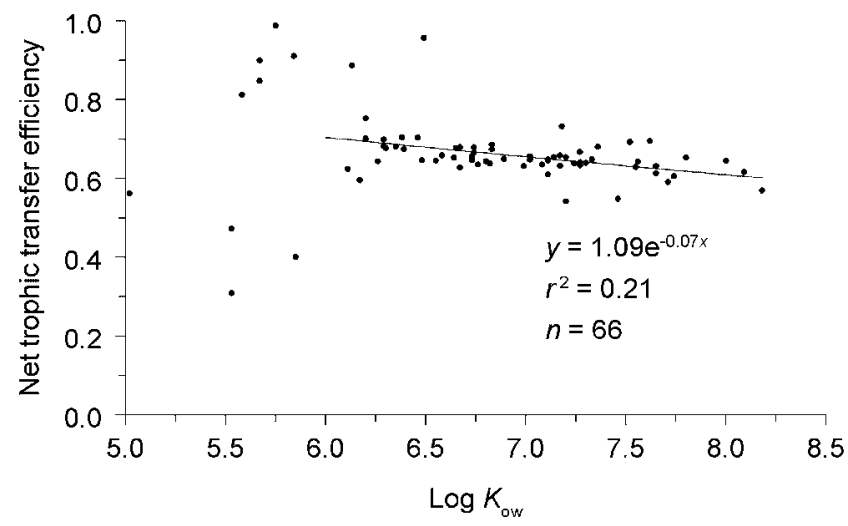

Fig. 2. Estimate of net trophic transfer efficiency $(\gamma)$ of a polychlorinated biphenyl (PCB) congener to lake trout from its prey as a function of the log $K_{\mathrm{Ow}}$ of the PCB congener. Estimates were based on a laboratory experiment, during which lake trout were fed bloater. Fitted regression line for congeners with $\log K_{\mathrm{OW}}$ greater than 6 is also displayed. The $r^{2}$ value for the fitted regression line represents the amount of variation in $\log \gamma$ explained by $\log K_{\text {OW }}$. 
toxicokinetics between lake trout and lake whitefish may provide insights into mechanisms by which PCB congeners are transported across the gut wall of fishes.

If elimination rates of the PCB congeners were very low or did not vary greatly from congener to congener or trended neither upward nor downward with increasing $\log K_{\mathrm{OW}}$, then we would expect gross trophic transfer efficiency of PCB congeners to lake trout from its prey to slightly decrease as $\log K_{\mathrm{OW}}$ increased from 6 to 10 . An alternative scenario would be that gross trophic transfer efficiencies were relatively high for all of the PCB congeners, but elimination and excretion rates slightly increased with increasing $\log K_{\mathrm{OW}}$. However, Buckman et al. [10] showed that short-term loss rates (loss rates within $30 \mathrm{~d}$ of the last feeding exposure) of the PCB congeners from rainbow trout actually decreased as $\log K_{\mathrm{OW}}$ increased from 5.2 to 6.5 but did not trend upward or downward when $\log K_{\mathrm{OW}}$ further increased from 6.5 to 8.0. In addition, long-term loss rates (loss rates after $30 \mathrm{~d}$ from the last feeding exposure) were practically negligible for the bulk of the PCB congeners with three or more chlorine atoms per molecule [10,20]. Therefore, unless PCB congener loss rates for lake trout were influenced by $\log K_{\mathrm{OW}}$ in a completely different manner from those observed for rainbow trout, we would expect gross trophic transfer efficiency in lake trout to slightly decrease as $\log K_{\mathrm{OW}}$ increased from 6 to 10 .

Our estimate of $\gamma$ for total PCBs not only corroborated earlier work by Madenjian et al. [21], but may have provided additional insight into factors affecting $\gamma$. We calculated total PCB concentration by summing the concentrations of the 75 single PCB congeners along with the concentrations of the seven pairs of co-elutors. Based on our PCB determinations and averaging across all eight tanks, $\gamma$ for total PCBs was estimated at 0.657. Based on fish tissue determinations for total PCB concentration rather than concentrations of $\mathrm{PCB}$ congeners, Madenjian et al. [21] estimated net trophic transfer efficiency of total PCBs to lake trout from its prey for lake trout feeding at low, medium, and high rates in laboratory tanks. Just as is the case for our experiment, the high feeding rates in the Madenjian et al. [21] experiment were achieved by allowing the fish to feed ad libitum during one feeding each day. Estimates of $\gamma$ for total PCBs at the low, medium, and high feeding rates were 0.873 , 0.912 , and 0.715 , respectively. Thus, the results suggested a decrease in $\gamma$ as feeding rate approached a high level [21]. Our estimate of $\gamma$ for total PCBs was slightly lower than the Madenjian et al. [21] estimate for lake trout feeding at a high rate. The fish feeding at a high rate in the Madenjian et al. [21] experiment averaged a consumption rate of $1.2 \%$ of their body weight per day, which was the same average feeding rate for our study. However, the lake trout in our experiment received a substantially higher amount of energy in their food compared with the lake trout in the Madenjian et al. [21] experiment, because the energy density of the bloater fed to the lake trout in our experiment was approximately $30 \%$ higher than the average energy density of the alewife (Alosa pseudoharengus) and rainbow smelt fed to the lake trout in the Madenjian et al. [21] study. Perhaps $\gamma$ is more strongly influenced by the rate of energy intake than the rate of food (expressed on a weight basis) intake. We would expect $\gamma$ to decrease as the rate of energy intake approached relatively high rates.

Given the reasonably close match in $\gamma$ between the active and inactive lake trout, we would predict that changes in lake trout activity would have a relatively minor effect on net trophic transfer efficiency of the PCB congeners. Considering the relatively high population densities of salmonines and the relatively low population densities of prey fish presently observed in the Laurentian Great Lakes, as well as the declining trend in lake trout energy density during 1995 to 2004 in the Laurentian Great Lakes, Paterson et al. [15] postulated that lake trout in the Laurentian Great Lakes have adjusted to changes in the food web by increasing their activity costs associated with feeding. Results from our experiment suggested that net trophic transfer efficiencies of the PCB congeners would not have been strongly affected by this hypothetical increase in lake trout activity level.

The relatively high variability in estimates of $\gamma$ for the lower chlorinated congeners may have been attributable, at least in part, to a decrease in the detection limit from the negative chemical ionization mass spectrometry method with increasing chlorination level [23]. Measurements near the detection limit often have relatively low precision and accuracy because of analytical error [24].

\section{CONCLUSION}

Based on results from a laboratory experiment, the influences of degree of chlorination and $\log K_{\mathrm{OW}}$ on the net trophic transfer efficiency $(\gamma)$ of PCB congeners to lake trout from its prey were relatively weak. Net trophic transfer efficiency of the PCB congeners exhibited a slight decline with increasing degree of chlorination and as $\log K_{\mathrm{OW}}$ increased from 6.0 to 8.2. Thus, lake trout were similar to fishes such as Atlantic salmon, rainbow trout, and coho salmon, in which $\gamma$ for PCB congeners was weakly affected by $\log K_{\mathrm{OW}}$ and degree of chlorination, but unlike lake whitefish, in which $\gamma$ for PCB congeners was strongly influenced by $\log K_{\mathrm{OW}}$ and degree of chlorination. The level of activity of the lake trout did not have a significant effect on $\gamma$.

\section{SUPPLEMENTAL DATA}

Table S1. Mean estimates of net trophic transfer efficiency $(\gamma)$ of pairs of polychlorinated biphenyl (PCB) co-eluting congeners to lake trout from its prey. Estimates were based on a 135-d laboratory experiment, during which bloater were fed to lake trout. For each pair of co-eluting congeners, $\gamma$ estimates from all eight tanks were averaged to yield the mean estimate. (29 KB DOC)

Acknowledgement-We thank E. Murphy for reviewing the first draft of this paper and providing helpful comments for improving the manuscript. This work was funded, in part, by the Great Lakes Fishery Commission. Use of trade, product, or firm names does not imply endorsement by the U.S. Government. This article is Contribution 1703 of the U.S. Geological Survey Great Lakes Science Center.

\section{REFERENCES}

1. Madenjian CP, Carpenter SR, Rand PS. 1994. Why are the PCB concentrations of salmonine individuals from the same lake so highly variable? Can J Fish Aquat Sci 51:800-807.

2. Madenjian CP, Elliott RF, Schmidt LJ, DeSorcie TJ, Hesselberg RJ, Quintal RT, Begnoche LJ, Bouchard PM, Holey ME. 1998. Net trophic transfer efficiency of PCBs to Lake Michigan coho salmon from their prey. Environ Sci Technol 32:3063-3067.

3. Thomann RV. 1989. Bioaccumulation model of organic chemical distribution in aquatic food chains. Environ Sci Technol 23:699-707.

4. Calabrese EJ, Baldwin LA. 1993. Performing Ecological Risk Assessments. Lewis, Boca Raton, FL, USA.

5. Madenjian CP, Schmidt LJ, Chernyak SM, Elliott RF, DeSorcie TJ, Quintal RT, Begnoche LJ, Hesselberg RJ. 1999. Variation in net trophic transfer efficiencies among 21 PCB congeners. Environ Sci Technol 33: 3768-3773. 
6. Jackson LJ, Schindler DE. 1996. Field estimates of net trophic transfer of PCBs from prey fishes to Lake Michigan salmonids. Environ Sci Technol 30:1861-1865

7. Gobas FAPC, Muir DCG, Mackay D. 1988. Dynamics of dietary bioaccumulation and faecal elimination of hydrophobic organic chemicals in fish. Chemosphere 17:943-962.

8. Madenjian CP, O'Connor DV, Rediske RR, O'Keefe JP, Pothoven SA. 2008. Net trophic transfer efficiencies of polychlorinated biphenyl congeners to lake whitefish (Coregonus clupeaformis) from their food. Environ Toxicol Chem 27:631-636.

9. Isosaarl P, Kiviranta H, Lie Ø, Lundebye AK, Ritchie G, Vartiainen T. 2004. Accumulation and distribution of polychlorinated dibenzop-dioxin, dibenzofuran, and polychlorinated biphenyl congeners in Atlantic salmon (Salmo salar). Environ Toxicol Chem 23:1672-1679.

10. Buckman AH, Brown SB, Hoekstra PF, Solomon KR, Fisk AT. 2004. Toxicokinetics of three polychlorinated biphenyl technical mixtures in rainbow trout (Oncorhynchus mykiss). Environ Toxicol Chem 23:1725-1736.

11. Burreau S, Axelman J, Broman D, Jakobsson E. 1997. Dietary uptake in pike (Esox lucius) of some polychlorinated biphenyls, polychlorinated naphthalenes and polybrominated diphenyl ethers administered in natural diet. Environ Toxicol Chem 16:2508-2513.

12. MacCrimmon HR, Gots BL. 1980. Fisheries for charrs. In Balon EK, ed, Charrs: Salmonid Fishes of the Genus Salvelinus. Dr. W. Junk bv Publishers, The Hague, The Netherlands, pp 797-839.

13. Martin NV, Olver CH. 1980. The lake charr, Salvelinus namaycush. In Balon EK, ed, Charrs: Salmonid Fishes of the Genus Salvelinus. Dr. W. Junk bv Publishers, The Hague, The Netherlands, pp 205-277.

14. Hansen MJ. 1999. Lake trout in the Great Lakes: Basinwide stock collapse and binational restoration. In Taylor WW, Ferreri CP, eds, Great Lakes Fishery Policy and Management: A Binational Perspective. Michigan State University Press, East Lansing, MI, USA, pp 417-453.

15. Paterson G, Whittle DM, Drouillard KG, Haffner GD. 2009. Declining lake trout (Salvelinus namaycush) energy density: Are there too many salmonid predators in the Great Lakes? Can J Fish Aquat Sci 66: 919-932.
16. Madenjian CP, David SR, Pothoven SA. 2012. Effects of activity and energy budget balancing algorithm on laboratory performance of a fish bioenergetics model. Trans Am Fish Soc 141: 1328-1337.

17. Schmidt LJ. 1997. Method for analysis of total PCBs and PCB congeners (full suite) and transnonachlor for gas chromatography/negative chemical ionization single ion mass spectrophotometry. Vol. II of Lake Michigan Mass Balance (LMMB) study methods compendium. Organic and mercury methods. EPA-905-R-97-012b. U.S. Environmental Protection Agency, Great Lakes National Program Office, Chicago, IL.

18. U.S. Environmental Protection Agency. 1999. Method 1668, Revision A: Chlorinated biphenyl congeners in waters, soil, and tissue by HRGC/ HRMS. EPA-821-R-00-002, Washington, DC.

19. Frame GM, Cochran JW, Boewadt SS. 1996. Complete PCB congener distributions for 17 Arochlor mixtures determined by 3 HRGC systems optimized for comprehensive, quantitative, congener specific analysis. J High Res Chromatogr 19:657-668.

20. Niimi AJ, Oliver BG. 1983. Biological half-lives of polychlorinated biphenyl (PCB) congeners in whole fish and muscle of rainbow trout (Salmo gairdneri). Can J Fish Aquat Sci 40:1388-1394.

21. Madenjian CP, O'Connor DV, Nortrup DA. 2000. A new approach toward evaluation of fish bioenergetics models. Can J Fish Aquat Sci 57: 1025-1032.

22. Hawker DW, Connell DW. 1988. Octanol-water partition coefficients of polychlorinated biphenyl congeners. Environ Sci Technol 22: 382-387.

23. Dmitrovic J, Chan SC. 2002. Determination of polychlorinated biphenyl congeners in human milk by gas chromatography-negative chemical ionization mass spectrometry after sample clean-up by solid-phase extraction. J Chromatogr B 778:147-155.

24. Zorn ME, Gibbons RD, Sonzogni WC. 1997. Weighted least-squares approach to calculating limits of detection and quantification by modeling variability as a function of concentration. Anal Chem 69: 3069-3075. 